\title{
The Attributional-Counterfactual Theory of Need: Integrating Theories to Predict Need Norm Use
}

\author{
Joseph T. Liu \\ Florida Gulf Coast University
}

\author{
Maria J. Mendez \\ California State University, Chico
}

\begin{abstract}
The justice literature has coalesced around the notion that actors (e.g., supervisors) tend to utilize the norm of equity for resource allocation decisions because it is generally considered most fair when employees who contribute more to the organization receive more resources. Yet, actors might sometimes utilize a need norm to allocate resources to those most in need. Studies that have addressed need-based resource allocations have assumed a relatively straightforward conceptualization of need. However, research from related areas suggests that multiple characteristics of the need itself could trigger actors' use of a need norm to allocate resources. We advance a theoretical framework that outlines various need characteristics that drive actors' use of a need norm. The framework draws on the processes outlined in attribution theory and integrates those with the content domains addressed in fairness theory. A discussion of the implications for justice, attribution, and fairness theory research follows.
\end{abstract}

Key Words: organizational justice, need, resource allocation norms, fairness theory, attribution theory

$\mathrm{F}$ airness concerns seem to dominate today's social and organizational landscape. Hot button issues like affirmative action (Son Hing, Bobocel, \& Zanna, 2002) have proponents advocating that a fair distribution of resources should be based on recipients' need and opponents who argue that it should be based on recipients' contribution and achievement instead. In many ways, these controversies beg the broader question of how limited resources ought to be allocated in organizations and fall under the purview of distributive justice, or the appropriateness of outcomes in resource allocation decisions (Adams, 1965; Colquitt, 2001). Distributive justice is evaluated in light of allocation norms that define whether distributions are perceived as fair, such as equity (based on individuals' dissimilar contributions), equality (all individuals receive the same resources), and need (based on individuals' dissimilar needs; Lamm \& Schwinger, 1980; Leventhal, 1976a). To date, the emphasis on equity is so prevalent that it is almost synonymous with distributive justice (cf. Colquitt, 2001) and is recognized by scholars as the "default" allocation norm 
evoked by individuals when they assess the fairness of resource allocation decision outcomes (Törnblom \& Kazemi, 2015).

A "need refers to any potential or actual deprivation of a required or desired resource" (Schwartz, 1975: 116). Thus far, the justice literature has been criticized as lacking research on needs (Rupp, Shapiro, Folger, Skarlicki, \& Shao, 2017), which have been described as being "lost in the shuffle" of fairness research (Baer, Frank, Matta, Luciano, \& Wellman, 2020:3). Moreover, very few studies have analyzed the characteristics of a need and their potential impact on the use of the need norm as a basis for resource allocation. Beyond that, none have forwarded a framework for organizing and understanding the theoretical content and interrelatedness of these need characteristics. This represents a significant gap in the literature because all needs are not created equal. For example, needs might vary in their urgency or in the extent to which they could have been prevented (Weiner, 2012). This is meaningful because the various characteristics and circumstances surrounding a recipient's need might differentially elicit the use of a need norm by actors-individuals who make resource allocation decisions (e.g., supervisors). In the present context of need, there is no theoretical framework for outlining, organizing, and understanding the characteristics of recipients' need as it relates to eliciting actors' use of a need norm to distribute resources.

To fill this gap, we developed the attributional-counterfactual theory of need (herein referred to as ACT; see Figure 1) by integrating two supplementary theories: fairness theory, which outlines the cognitions used by individuals to judge the fairness of actions (Folger \& Cropanzano, 2001), and attribution theory, which describes the processes underlying causal explanations for events (Weiner, 2006). Combining these two theories, ACT examines the characteristics of a need through the lens of the three counterfactual cognitions proposed in fairness theory (i.e., would, could, and should counterfactuals) and arranges them in a temporal sequence informed by attribution theory. Finally, ACT positions sympathy (a central process in attribution theory; Weiner, 2006) as an affect-based mechanism through which a counterfactual, cognitive analysis affects actors' use of a need norm to allocate resources.

This article offers three important contributions. First, ACT supplements the extant justice literature that has predominantly emphasized the equity norm (Törnblom \& Kazemi, 2015) by explaining the use of need allocation norms based on a need's characteristics. In doing so, this theory integrates various need characteristics that have been addressed in piecemeal into a comprehensive theoretically driven framework that elucidates the content, nature, interrelatedness, and consequences of need characteristics.

Second, our integration of attribution theory and fairness theory results in the mutual advancement of both theories. Attribution theory provides a theoretical foundation for identifying specific need characteristics that predict counterfactual thinking within the three broad domains outlined in fairness theory (i.e., wellbeing, conduct, and principles). Moreover, while fairness theory's cognitive focus does acknowledge the likelihood of general affective responses to counterfactuals (Cropanzano, Weiss, Suckow, \& Grandey, 2000), attribution theory (Weiner, 


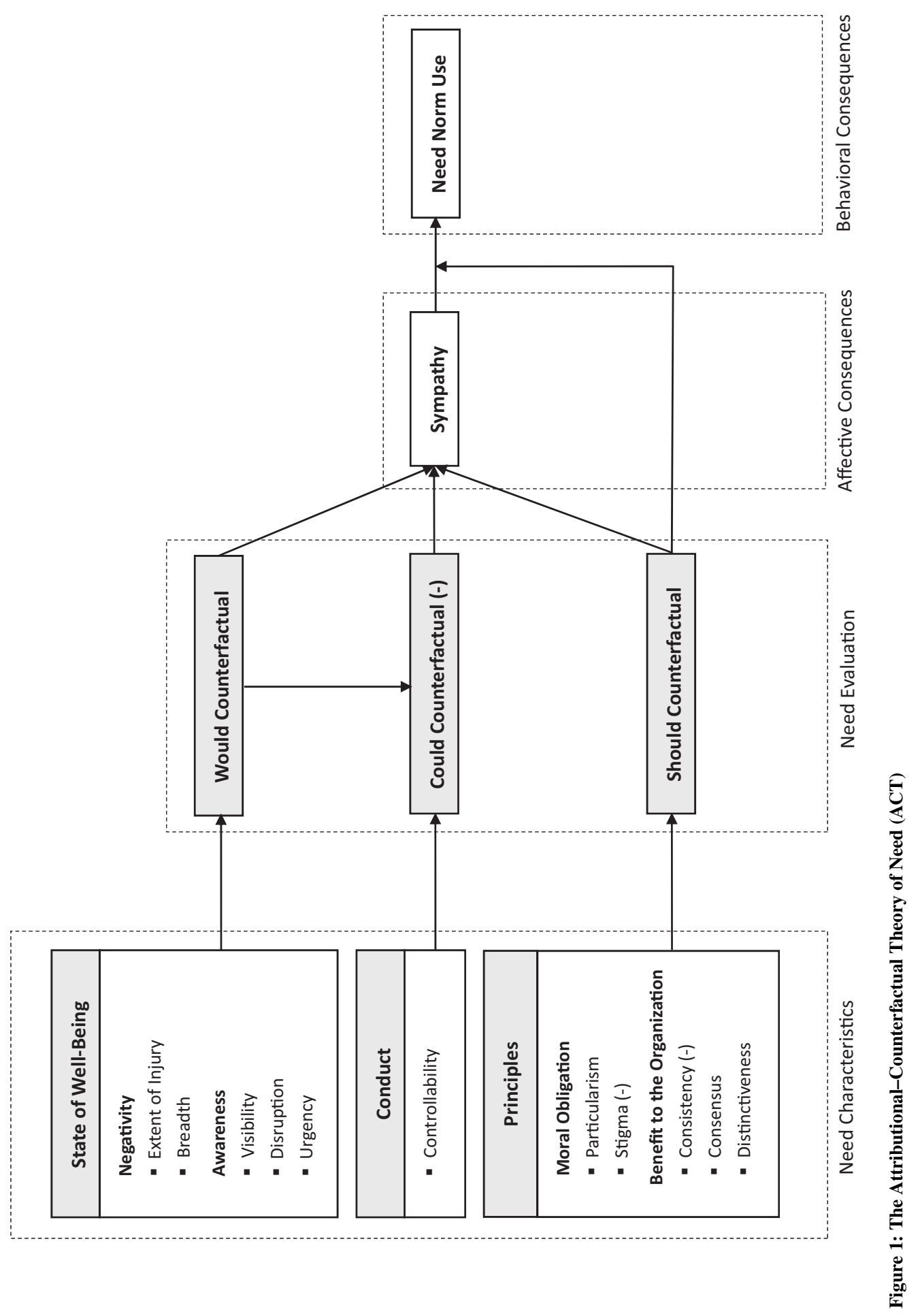


2006) identifies sympathy as the specific affective mediational process that might serve as the link between counterfactual thinking and behavioral consequences (e.g., supervisors' use of a need norm to allocate resources). This synthesis linking sympathy to an actor's use of a need norm represents a contribution to fairness theory given that "neither fairness theory nor deonance theory is explicit about the behaviors that might be spontaneously triggered by moral emotions" (Colquitt \& Zipay, 2015: 88) and is especially important in light of the impact affect plays in justice enactment (Scott, Colquitt, \& Paddock, 2009; Scott, Garza, Conlon, \& Kim, 2014). In addition, previous researchers have noted that the temporal ordering of the three fairness theory counterfactuals is somewhat arbitrary and follows no predictable sequence, depending instead on the circumstances (Folger \& Cropanzano, 1998). Yet the processes outlined in attribution theory provide a theoretical basis for explicating a predominant temporal ordering. Similarly, an integration of fairness theory with attribution theory also provides some important insight into the attribution process. Given that Weiner's (1985a) theory was developed in the education setting, it is fairly silent on the organizational factors that might influence the attribution and decision-making process. In contrast, fairness theory (Folger \& Cropanzano, 2001) is better positioned to address potential moderators stemming from the organizational context because it was originally developed, and has been primarily examined, in the context of organizational decision-making.

Third, whereas the actor (and his or her past decisions) has been the target of the counterfactual judgment process outlined in fairness theory (Folger \& Cropanzano, 2001), the present model places the recipient's need as the target of counterfactual thinking. Specifically, rather than focusing on a recipient's judgment of an actor's decision ex post facto, ACT shifts the focus of counterfactuals to an actor's judgment of a recipient's need characteristics that could induce an actor's use of the need norm. This allows for an understanding of what causes an actor to make this decision in the first place. Besides answering calls to understand what causes supervisors to act fairly (Scott et al., 2014), this theoretical perspective reveals novel predictors not previously addressed in research. These predictors, which focus on the recipient and his or her need, might provide more actionable guidance to needy recipients (e.g., persons with disabilities, women who are pregnant) specifically as it relates to framing and managing perceptions of actors who are in positions of power and charged with allocating scarce resources. That is, knowing what need characteristics make an actor "tick" will allow recipients to convey and communicate their needs in a way most likely to induce an actor's use of the need norm.

\section{A REVIEW OF FAIRNESS THEORY AND ATTRIBUTION THEORY}

\section{Fairness Theory}

Fairness theory posits that fairness judgments flow from assessments of an authority figure's accountability. Assessments of accountability, in turn, result from the consideration of three counterfactuals, which are mental simulations of possible 
alternatives that are, quite literally, contrary to the facts (Folger \& Cropanzano, 2001). Counterfactuals are a form of cognitive judgment wherein a decision is unfair to the extent that three hypothetical questions are answered in the affirmative (Colquitt, Greenberg, \& Zapata-Phelan, 2005: 38):

1. Would counterfactual: "Would I have been better off if a different outcome or procedure had occurred? In other words, have I experienced some injury?"

2. Could counterfactual: "Could the authority have behaved differently? In other words, were there other feasible courses of action?"

3. Should counterfactual: "Should the authority have behaved differently? In other words, were moral and ethical standards violated?"

For instance, an employee is likely to decide that a written reprimand is unfair because it will cost him a salary increase that he was expecting, his supervisor could have talked to him and pursued an alternative resolution before applying this punishment, and such a severe punishment was inappropriate for the offense. Collectively, these counterfactuals (known as the would, could, and should counterfactuals) suggest that judgments of fairness are driven by individuals' concerns in three primary domains: states of well-being (for would counterfactuals), individual conduct (for could counterfactuals), and moral or ethical principles (for should counterfactuals; Colquitt et al., 2005).

Despite the wealth of studies conducted on fairness theory, several gaps remain in the literature. First, the extant justice literature has predominantly focused on applying counterfactuals to an actor's decisions to assess his or her fairness after the decision has already been made (e.g., Nicklin, Greenbaum, McNall, Folger, \& Williams, 2011). This ignores other factors pertaining to the recipient that can affect an actor's decisions and thus fails to acknowledge the possibility of counterfactuals performed by the actor while making an allocation decision. In addition, the causal ordering of fairness theory's counterfactuals has been deemed arbitrary, with no predictable or predominant sequence of would, could, or should counterfactuals (Folger \& Cropanzano, 1998). Specifically, Folger and Cropanzano state that "the Would, Could, and Should factors do not occur in any particular order. . . . Sometimes accountability is determined prior to knowledge of impact. . . Alternatively, damage to company property might be evident before the perpetrator is discovered" (181). Furthermore, even though they can be justified theoretically, fairness theory lacks any mention of mediators. Specifically, it is currently unclear what intervening processes (and perhaps moderators of these processes) lead counterfactuals to eventually impact behaviors and decisions. Finally, fairness theory's focus on cognition (in the form of counterfactual thinking) was intended as a bridge between the justice and emotion literatures (Cropanzano et al., 2000), yet the specific emotion(s) relevant to the use of various distributive justice allocation norms (in general) and the need norm (in particular) remain unaddressed. This may be a fruitful area of inquiry given the large role of affect in fairness phenomena (Colquitt et al., 2013). Altogether, these gaps can be advanced by integrating fairness theory with processes outlined in attribution theory. 


\section{Attribution Theory}

Attribution theory explains how information is used to arrive at causal explanations that then differentially motivate decision-making (Weiner, 2006). For example, a supervisor will use available information to determine why an employee has recently demonstrated lower performance; that causal assessment will then help the supervisor decide whether a low performance evaluation or additional training is more appropriate. One of the most popular theories in this literature, Weiner's (1985a) attributional theory of achievement motivation and emotion, describes various dimensions of causal explanation. For example, controllability is the extent to which the cause of an individual's status is perceived to be under the individual's volition (Weiner, 1979).

Interestingly, Weiner's (1985a) theory describes the attribution process in counterfactual terms. Specifically, Weiner (2012: 144, emphasis added) states that "ability and effort give rise to different evaluations because of their contrasting placement on the causal dimensions of control. Lack of effort is a controllable cause; it 'could have been otherwise." While this phrasing is presumably unintentional, Weiner's couching of attributions as an exercise in counterfactual thinking underscores the potential for attribution theory and fairness theory to meaningfully integrate with and supplement each other.

\section{Fairness Theory, Attribution Theory, and ACT: Parallels and Distinctions}

A preliminary understanding of ACT can be achieved by comparing ACT with the two theories that serve as its namesake. First, all three theories have some interesting parallels, chief of which is a common emphasis on utilizing information to hold an individual accountable for his or her status to determine one's reactions and behaviors toward that individual (Folger \& Cropanzano, 2001; Weiner, 1985a). Whereas attribution theory is agnostic as to the target of this accountability assessment (Martinko \& Thomson, 1998) and fairness theory targets an authority figure (Folger \& Cropanzano, 2001), ACT directs this process toward the characteristics of an individual's need. A theory of need construed entirely within fairness theory would focus on the extent to which an individual is held accountable for his or her need, which would dictate the extent an actor feels inclined to use the need norm to allocate resources. For example, if the needy individual is not held accountable, the need is unfair, and the actor would feel the urge to remedy the situation by allocating to the need. ACT integrates and builds on this foundation by further detailing 1) the specific need characteristics relevant to an actor's judgment of the individual's accountability and 2) the specific mechanisms of this process, including the interrelationships between different types of counterfactuals and the identification of sympathy as an affective mechanism by drawing from attribution theory (Barrett, Tugade, \& Engle, 2004).

ACT also draws from and builds on attribution theory's causal search process. Weiner's (2006) theory on social motivation and justice provides a good example of what a "pure" attribution theory might look like as it relates to predicting an actor's use of a need norm. In it, Weiner (2006) describes the accountability assessment 
process as being determined by a causal search focused on the controllability and intentionality of an individual's conduct. When an individual's conduct is controllable and intentional as it relates to his or her status (e.g., need), the individual is deemed accountable for his or her status, and help is likely to be withheld. While attribution theory is focused on conduct, ACT expands on this notion to include other domains beyond conduct to derive relevant need characteristics that predict an actor's need norm use. These broad domains are borrowed from fairness theory, while additional specific need characteristics are drawn from other relevant attribution dimensions (e.g., Kelley, 1967) and seminal theorizing in the justice literature (e.g., Leventhal, Karuza, \& Fry, 1980). Altogether, ACT builds on fairness theory and attribution theory to describe what characteristics of a need might elicit the use of the need norm and how this process occurs.

\section{A REVIEW OF RESOURCE ALLOCATION NORMS}

Scholars have identified three primary resource allocation norms (Cropanzano, Fortin, \& Kirk, 2015): equity, equality, and need. Equity focuses on distributing resources in proportion to one's contributions (Leventhal, 1976a). The equality norm prescribes that resources be distributed equally among all parties. Finally, need dictates that resources be given to individuals most in need, regardless of contributions (Deutsch, 1975; Leventhal, 1976a). Though additional allocation rules have been identified, most can be categorized within the equity, equality, and need paradigms (Törnblom \& Kazemi, 2015).

Of the three allocation norms, the justice literature has coalesced around the equity norm. For example, the most popular operationalization of distributive justice, by Colquitt (2001; for a review, see Colquitt \& Rodell, 2015), exclusively utilizes an equity allocation norm. To date, several meta-analyses and qualitative reviews (e.g., Colquitt, Conlon, Wesson, Porter, \& Ng, 2001; Colquitt \& Zipay, 2015) document the importance of distributive justice (conceptualized as equity) in impacting employees' attitudes and behaviors. However, and despite the valuable insights equity theory has brought to the understanding of fairness, authors have recognized that equity is not the appropriate allocation norm in every situation (Deutsch, 1975; Leventhal, 1976a, 1976b). For example, Cropanzano et al.'s (2015) review concludes that the equality allocation norm often serves as a resource allocation heuristic when cognition-based processing is infeasible because of high cognitive demands. Furthermore, scholars have advocated for the importance of addressing the role of recipient need in resource allocation decisions (Baer et al., 2020). While both equality and need seem to be underresearched in relation to equity, ACT begins with deliberative (vs. heuristic-based) processing of justice perceptions. As a result, ACT primarily focuses on an actor's use of the need norm.

\section{Need Characteristics and Need-Based Resource Allocation}

Despite some progress in examining need-based allocations, the extant literature has focused on predictors that are exogenous to the need (i.e., factors other than the characteristics and features of the need itself). Indeed, prior studies have found that 
contextual factors, such as group setting or national and organizational culture, influence the likelihood that actors utilize a need allocation norm (e.g., He, Chen, \& Zhang, 2004; Kim, Park, \& Suzuki, 1990; Mannix, Neale, \& Northcraft, 1995; Poepsel \& Schroeder, 2013; Webb Day, Holladay, Johnson, \& Barron, 2014). Similar effects have been found in studies that examine intraindividual factors of the actor, such as empathy or affect (e.g., Blader \& Rothman, 2014; Cropanzano, Massaro, \& Becker, 2017). There are a few notable exceptions to this trend. Leventhal and colleagues (Leventhal, 1976a, 1976b; Leventhal et al., 1980) theorized a series of factors that predict actors' need norm use, some of which could be described as need characteristics (e.g., need scarcity, need harmfulness). Conlon, Porter, and Parks (2004) distinguish between needs driven by personal reasons and those driven by business reasons. They find that allocations based on business needs (vs. personal needs) tend to activate the use of a need allocation norm and are thus perceived as more fair. For example, allocating more resources to an employee whose greater need is driven by compliance with business regulations is likely to be viewed as more fair than when the need is perceived to be driven by a problem in the employee's personal life. Another set of studies by Skitka and Tetlock (1992) examined the internality/controllability (Weiner, 2012) of the cause that led to the need. They found that needs attributed to less controllable (e.g., aptitude) and more external (e.g., situational) causes show a greater tendency to elicit the use of need allocation norms.

The body of literature reviewed herein illustrates a few aspects of our conceptualization of need. First, the definition of need as a deprivation of a resource is quite broad. Specifically, resources "can be defined as anything which people may have an interest in having or using (e.g., health, wealth, deference, skill)" (Schwartz, 1975: 112). Similarly, the various descriptors of a need (presently referred to as characteristics) are also quite inclusive. As partly exemplified earlier, need characteristics can encompass the causes of a given state of well-being (Skitka \& Tetlock, 1992), the domain of a need's impact if left unaddressed (Conlon et al., 2004), the incidence rate within an organization, the costs associated with a need, or any number of constructs that can describe and differentiate one need from another. To advance these initial findings, we present a theoretically driven framework that integrates various need characteristics that can impact an actors' need norm use. Our goal is not to provide an exhaustive list of need characteristics, as such endeavors do not necessarily constitute theory (Sutton \& Staw, 1995). Instead, our theory is an initial foray intended to draw on and integrate fairness theory and attribution theory to identify the most crucial need characteristics that ultimately predict an actor's need norm use (Weick, 1995).

\section{THE ATTRIBUTIONAL-COUNTERFACTUAL THEORY OF NEED: A FRAMEWORK FOR NEED ALLOCATION NORM USE}

The attributional-counterfactual theory of need draws from the three fairness theory counterfactual domains to outline need characteristics that can elicit an actor's use of the need norm. Specifically, the would, could, and should counterfactuals speak to 1) a needy recipient's state of well-being, 2) a recipient's conduct and alternative 
courses of action with respect to his or her need, and 3) the ethical principles surrounding a need-based allocation to the recipient, respectively. We use attribution theory to advance these counterfactual domains to detail the specific need characteristics that drive an actor's counterfactual thinking, resulting in a theoretically based taxonomy of need characteristics. Attribution theory is then used to describe how need characteristics differentially elicit an actor's counterfactual thinking and need norm use. This elucidation is based on Weiner's (1985a) attributional theory of motivation and emotion, which serves as the basis to support the temporal ordering of these counterfactual thoughts and the identification of sympathy as a critical affective mechanism that links counterfactual thinking to need norm use (Weiner, 2006).

\section{Taxonomy of Need Characteristics and Counterfactual Thinking}

Past literature has evaluated and described a need's magnitude along a single continuum (i.e., less need or more need; Martin \& Harder, 1994; see also Conlon et al., 2004; He et al., 2004; Mannix et al., 1995), where more need likely elicits the use of a need norm (Skitka \& Tetlock, 1992). In Skitka and Tetlock's study, for instance, participants were asked to assume the role of a decision maker responsible for allocating organs for transplants where "high need in the organ context was operationally defined as having a $1 \%$ chance of surviving until another organ became available ... [and] low need placed that chance at 10\%" (502). In this study, the distribution of resources was evaluated by considering the negative consequences for each potential recipient (chance of survival) derived from being denied a specific resource (a transplant). In other studies, need is treated as a unidimensional black box, described as high or low without providing insight into the factor or factors that drove this assessment. This is the case for Conlon and colleagues' (2004: 337) study, in which researchers manipulated participants' perceptions of need using a statement that read: "A colleague has told you that your manager chose the employees he thinks have the greatest personal need to be unaffected by the salary reductions."

However, actors' perceptions of the magnitude of a need and, therefore, their decisions to use a need allocation norm are likely to respond to a variety of need characteristics. To advance current understanding, need must be studied as a multifaceted construct, as suggested in the disability literature (Stone \& Colella, 1996). In ACT, we integrate past literature and propose a taxonomy that categorizes need characteristics based on the three content domains associated with counterfactuals in fairness theory: state of well-being, conduct, and ethical principles (Colquitt et al., 2005; Weiner, 1985b).

\section{State of Well-Being and Would Counterfactuals}

The most frequently studied need characteristic is the perception that the recipient is in an unfavorable state of well-being relative to a point of reference. For instance, the disabilities literature often compares a person's current well-being to the person's well-being prior to the onset of the disability or to that of a person without a disability (Colella, 2001; Stone \& Colella, 1996). This suggests that need norm use increases 
in proportion to the discrepancy between an individual's perceived state of wellbeing and a given reference point. This can be construed as a form of counterfactual thinking wherein a recipient's perceived current well-being is compared to a hypothetical and/or imagined alternative reference point. Of the three counterfactuals, would counterfactuals are most likely to be elicited under these circumstances because would counterfactuals are directed at understanding and making decisions related to states of well-being (i.e., "Would I have been better off if a different outcome had occurred?" addresses one's state of well-being).

Judgments of a recipient's state of well-being can also be impacted by the level of awareness of a need. Schwartz's (1975) theory on the justice of need proposes that a judgment of need is driven by the awareness that an individual is lacking some desired resource and that this lack of resources is accompanied by negative consequences. This underscores two related categories of need characteristics relevant to an actor's assessment of a recipient's state of well-being: 1) the negative effect that a need creates on the recipient's well-being (i.e., negativity) and 2) the actor's awareness of the recipient's state of well-being (i.e., awareness). Similarly, attribution theory (Weiner, 1985a, 1985b) argues that more negative and attention-capturing events are more likely to initiate attributional processes (Berscheid, Graziano, Monson, \& Dermer, 1976). Consequently, the two associated categories of negativity and awareness serve as a basis for predicting an actor's would counterfactual thinking in ACT.

\section{Negativity}

The negativity of a need captures the unfavorable effects of the need on the recipient's well-being (Skarlicki \& Kulik, 2004). The perception of negative consequences triggers imagined alternative states (i.e., counterfactual thinking), such as "would this employee be better off if she had not lost her home to a fire?" (Schwartz, 1975). Within the general psychology literature, negative impacts are thought to vary in both their direct consequences and their indirect consequences (Sweeny, 2008). Direct consequences reflect the depth of a recipient's unfavorable change in status, whereas indirect consequences reflect the extensiveness, or breadth, of effects (Sweeny, 2008). Building on this notion, we propose that need negativity is driven by two need characteristics that capture the depth and breadth of negativity, respectively (see Figure 1).

The first characteristic is the extent of the injury provoked by the need; greater injuries are perceived as more negative, reflecting the depth of the need's negativity. For example, in their experimental study discussed previously, Skitka and Tetlock (1992) presented their subjects with cases in which they manipulated the patient's extent of injury by varying the patient's chance of survival without a new organ. Second, the negativity of a need is also explained by its breadth, or the extent to which the need affects various domains of an individual's life. A need with a large breadth will negatively impact job-related, social, physical, and religious aspects of one's life and thus be perceived as more negative. In the example of an employee's house being lost in a fire, use of the home as a place of business in addition to as a residence would increase the breadth of the need. 
Weiner's (1985a) attribution theory notes that negative events evoke cognitive activity because they arouse our natural desire to make sense of a situation. We propose that the more negative a need is (i.e., increased extent of injury and breadth), the more would counterfactual thinking is likely elicited. Specifically, greater negativity in a recipient's need causes an actor to engage in greater would counterfactual thinking because would counterfactuals are focused on sense making in the well-being domain, and need negativity speaks directly to a recipient's current state of well-being (Nicklin et al., 2011). Furthermore, need negativity increases the discrepancy between the current state of well-being and a given hypothetical reference point. For instance, the state of well-being of a professional athlete who suffers major back pain is further from the reference point of a whitecollar employee with a healthy back. The major back pain case would produce stronger would counterfactual thinking due to greater extent of injury and breadth (i.e., the injury affects professional and personal domains). Thus the components of negativity should be positively related to an actor's would counterfactual thinking:

Proposition 1a: A need's extent of injury will increase an actor's would counterfactual thinking.

Proposition 1b: A need's breadth will increase an actor's would counterfactual thinking.

\section{Awareness}

Awareness reflects the extent to which a need directs an actor's attention toward a recipient's current state of well-being. If an actor is less aware of a recipient's unfavorable state of well-being, the actor is less likely to seek to understand and consider that need. In other words, the actor may be more prone to inadvertently ignoring the need. In contrast, a need high in awareness draws in an actor's cognitive resources as he or she processes and makes a judgment regarding the recipient's current state of well-being. This argument is consistent with attribution theory, in which more important events are more likely to evoke cognitive activity and sense making (Weiner, 1985b). In the present case, ACT proposes that awareness likely induces an actor's would counterfactual thinking as he or she seeks to comprehend and evaluate the need.

Frameworks from cognitive psychology provide the structure of awareness utilized in ACT. A recent review identifies preattention, reorienting, and sensory amplification as critical processes that determine individual attention toward stimuli (Carretié, 2014). Preattention involves the unconscious elicitation of awareness of a stimulus as the individual engages with the environment. Reorienting involves redirecting processing resources to stimuli considered important. Finally, sensory amplification consists of the conscious modulation of attentional resources so that the processing of the important stimulus is maintained rather than reoriented to other stimuli (Serences \& Yantis, 2007). For example, while walking through a garden, a unique flower may catch the corner of a botanist's eye, evoking preattentive 
processes that cause them to perceive the existence of the flower. At the same time, the cognitive resources previously directed toward walking through the garden may be reoriented to admiring the flower. Finally, through sensory amplification processes, they may consciously maintain their attention on the flower while ignoring other distractions in the garden. In ACT, the three processes explain the aspects of a need that draw attention from the actor, thereby stimulating cognitive processes of awareness and, consequently, facilitating would counterfactual thinking. These three need characteristics (visibility, disruption, and urgency) are discussed in the following pages.

First, visibility is likely to draw preattention to a need, making the actor more cognizant of its existence (cf. Stone \& Colella, 1996). Needs low in visibility are difficult to detect and often require effort on behalf of the recipient to disclose his or her need to the actor (Sabat et al., 2014). Recipients themselves might be uncertain of their own unfavorable states of well-being when the need is less visible (Santuzzi, Waltz, Finkelstein, \& Rupp, 2014). This perhaps explains why individuals often discount the negative effects of less visible needs, such as mental illness (McLaughlin, Bell, \& Stringer, 2004). For actors, the sense of "conviction and validity" that accompanies more visible needs establishes a need's presence and lays the groundwork to make sense of the recipient's situation, increasing would counterfactual thinking (Slaughter, Cable, \& Turban, 2014).

Another need characteristic is disruption, or the extent to which a need produces discontinuities in recipients' work or life situations (Gersick, 1991; Swider, Liu, Harris, \& Gardner, 2017). For example, the adoption of a toddler is much more disruptive for an employee who is a first-time parent than one who already has a school-aged child. Though both employees have one additional child to care for, the amount of change in their lives from before to after the adoption varies. Given that reorientation involves a shift of attention from one stimulus to another (Carretié, 2014), a more disruptive need likely demands a correspondingly larger reorientation to draw cognitive resources away from other stimuli to the need, in order to facilitate its comprehension. As a result, an actor's awareness of a need is greater because the actor directs attention to analyzing the state of well-being caused by a disruptive need, which should increase an actor's would counterfactual thinking. Given that individuals can be cognitive misers (Fiske \& Taylor, 2013), less disruptive needs probably do not seem worthy of cognitive processing via would counterfactual thinking, especially considering the similarity in recipients' situations prior to and following a less disruptive need. Conversely, disruption likely produces a starker contrast in an actor's mind when he or she compares the current unfavorable state to the more disparate, and favorable, prior state. This contrast should increase an actor's would counterfactual thinking.

Finally, a need may vary in the extent to which it requires an immediate response, or its urgency. The need of an employee who will undergo surgery on Friday is more urgent than the need of an employee who will go through a similar procedure in six months and is therefore more likely to amplify, through the use of more cognitive resources, an actor's attention to the need. It is also more likely to elicit would counterfactual thinking, for two reasons. First, an urgent need is more difficult to 
ignore or dismiss, likely increasing an actor's motivation to engage in imagined thinking (Amabile, 1985), in this case by exploring would counterfactuals vis-à-vis the need. Additionally, urgency likely causes an actor to prioritize making sense of the need and prevents the reorientation of his or her attention to other unrelated cognitive tasks. As a result, the actor's focus and cognitive resources are drawn into the counterfactual thinking process, increasing the actor's ability to consider a needbased allocation through counterfactuals (Kanfer \& Ackerman, 1989) and ultimately increasing the intensity with which he or she engages in would counterfactual thinking as it relates to understanding a recipient's state of well-being:

Proposition 2a: A need's visibility will increase an actor's would counterfactual thinking.

Proposition 2b: A need's disruption will increase an actor's would counterfactual thinking.

Proposition 2c: A need's urgency will increase an actor's would counterfactual thinking.

\section{Conduct and Could Counterfactuals}

Could counterfactuals are broadly directed at understanding individual conduct (Folger \& Cropanzano, 2001). In the present case, making sense of recipients' needs involves understanding and judging their conduct as it relates to the need. This dovetails with a basic attribution theory premise. Previously applied to the case of help giving (Brickman, Rabinowitz, Karuza, Coates, Cohn, \& Kidder, 1982), attribution theories suggest that actors desire to establish the extent to which a recipient is accountable for his or her problem by looking to the past (Brickman et al., 1982) and understanding the role another's conduct played in causing the recipient's current status (Weiner, 1985a). Attribution theory refers to this notion as controllability (Weiner, 2012). Whereas other causal dimensions in attribution theory are orthogonal to one's conduct (Weiner, 2010) and/or consider the impact of the situation (Mantler, Schellenberg, \& Page, 2003), controllability primarily focuses on an individual's conduct (Weiner, 2010).

\section{Controllability}

Controllability is the extent to which the causes of a need are under the volitional control of the recipient (Skitka \& Tetlock, 1992). When a need is perceived to be high in controllability, the actor will be prone to imagining alternative ways in which the recipient could have prevented finding himself or herself in need, thus engaging in could counterfactual cognitions. For example, obesity is often perceived to be controllable (Ebneter, Latner, \& O'Brien, 2011), so a necessary workplace accommodation request is more likely to generate could counterfactuals when it is due to obesity than when it is due to another condition that is perceived to be less controllable, such as a genetic disorder. While the focus of this controllability calculus is on the recipient's conduct, other information may be attended to by actors (and impact 
could counterfactual thinking) insofar as it informs his or her judgments of a need's controllability. An actor may even consider the extent to which the actor's own conduct impacted the controllability of a recipient's need (Brickman et al., 1982) through counterfactuals directed at himself or herself, as in the case of a subordinate's workplace injury due to a supervisor's mishandling of equipment. Indeed, causal attributions that more heavily weigh the actor's conduct may reduce perceptions of a need's controllability (Brickman et al., 1982).

Weiner (2012: 144, emphasis added) describes controllability in terms of a could counterfactual: "Ability and effort give rise to different evaluations because of their contrasting placement on the causal dimensions of control. Lack of effort is a controllable cause; it "could have been otherwise." In support of this notion, higher controllability has been found to trigger less frequent resource allocation to a needy recipient (Skitka \& Tetlock, 1992). Integrating attribution and fairness theories as they relate to controllability, we propose that the perception that a need is caused by a recipient's volitional conduct results in greater could counterfactual thinking (e.g., "the recipient could have done something to avoid his or her current unfavorable state of well-being"). In this way, the ACT draws from Skitka and Tetlock's (1992) contingency model of distributive justice to identify controllability as a critical factor that drives could counterfactual thinking; thus we have the following proposition:

Proposition 3: A need's controllability will increase an actor's could counterfactual thinking.

\section{Principles and Should Counterfactuals}

Although an actor might be aware of a recipient's need, the actor may not feel ethically obliged to provide assistance (Leventhal et al., 1980). Following the exploration of the consequences and causes of a need, ACT analyzes a third group of need characteristics that explain the factors that compel an actor's need norm use. These factors trigger consideration of ethical principles associated with resource allocation decisions. Consistent with the deontic approach that is explicit in fairness theory (Folger, Cropanzano, \& Goldman, 2005), this decision process likely manifests as should counterfactual thinking.

As mentioned earlier, past fairness theory research has focused on actors' decisions ex post facto, that is, after decisions have already been made. In these cases, the should counterfactual process involves judging an actor's past decisions in comparison to a hypothetical alternative that conforms to relevant ethical principles (e.g., Nicklin, 2013; Nicklin et al., 2011). In contrast, ACT's should counterfactual thinking analyzes the differential ethicality of two alternatives for a decision that has yet to be made: a need norm allocation and the more commonly used equity norm (Folger, 1994, 1998). The greater the ethicality of a need norm compared to that of the default equity norm, the more likely it is that it will trigger an actor's consideration of the implications of a need-based resource allocation (i.e., greater should counterfactual thinking). Ultimately, these should counterfactuals weigh the ethical imperative of a need norm vis-à-vis an equity norm, and the decision that is more 
consistent with ethical principles is determined to be more appropriate (Folger \& Cropanzano, 2001).

We propose that specific characteristics of a need highlight the ethical discrepancies between need and equity allocations and therefore incite an actor's should counterfactual thinking. Leventhal and others (1980) argue that a need norm allocation can be motivated by a social responsibility toward advancing recipients' wellbeing in the social system and also by pragmatic reasons associated with the goals of the social system, as the actor has an ethical responsibility to act in ways that benefit the social system the actor represents (Leventhal, 1976a). Therefore we argue that an actor is presented with two general and related sets of principles to examine the ethicality of resource allocation: 1) principles of social responsibility (to which we refer as moral obligation) and 2) principles of responsibility toward the organization that he or she represents (to which we refer as benefit to the organization). Need characteristics under each of these two sets of principles are discussed in the following sections.

\section{Moral Obligation}

Actors may consider the option of using a need norm because they believe that it represents the morally responsible thing to do (Berkowitz, 1972). For instance, a manager can feel a moral responsibility to dedicate long hours to informally mentoring a young supervisor who struggles to connect with his or her team and attain good results, rather than seeking a replacement for this position. Early studies by Berkowitz (Berkowitz \& Connor, 1966; Berkowitz \& Daniels, 1964) and Feldman (1968) found evidence of helping behaviors motivated by social responsibility rather than social exchange. However, the potency of social responsibility to motivate resource allocation decisions is likely to vary, as some characteristics of the need itself activate or deactivate an actor's feelings of responsibility. We argue that an actor is more likely to feel socially responsible for a recipient that is highly dependent on him or her (Berkowitz \& Connor, 1966; Berkowitz \& Daniels, 1963) and less likely to feel this responsibility when the need is socially stigmatized (Leventhal, 1976a; Leventhal et al., 1980).

On one hand, an actor is more likely to use a need norm if the actor has a "feeling of personal responsibility for the recipient's welfare" (Leventhal, 1976a: 124). Drawing from prior theory on social resources (Foa \& Foa, 2012; Foa \& Foa, 1980), this feeling of personal responsibility is likely elicited by a need's particularism, or the extent to which the need can only be alleviated by the focal actor. In this regard, needed resources vary in how universal versus particular they are to an actor. Money is a highly universal resource that is equally valuable when provided by one person or another; needs associated with relationships, on the other hand, tend to be highly particular to specific individuals (Foa \& Foa, 1980). For example, high-quality leader-member exchange (LMX) relationships (Martin, Guillaume, Thomas, Lee, \& Epitropaki, 2016) take significant time and energy to develop (Graen \& Uhl-Bien, 1995), and their benefits cannot be easily substituted. Another relationship-related need that is high in particularism is recognition (Markham, 
Scott, \& McKee, 2002), which is more meaningful when fulfilled by specific persons. Particularism bears great significance for the selection of a need allocation norm because it activates feelings of social responsibility for the recipient's welfare (Leventhal, 1976a). Berkowitz and others' experiments demonstrated that actors make a greater effort to help (Berkowitz \& Daniels, 1963) and feel a stronger social responsibility for (Berkowitz \& Connor, 1966) recipients who are highly dependent on them, that is, when the particularism of their need is high. We argue that the particularism of a need creates a moral imperative for the actor by imbuing a sense of personal responsibility for the recipient's welfare (Leventhal, 1976a). In contrast, a less particular need likely results in a diffusion of the actor's responsibility to address the need (Skarlicki \& Kulik, 2004), which decreases should counterfactual thinking by lowering the actor's felt moral obligation to use a need norm.

On the other hand, actors are less likely to feel social responsibility for the recipient when the need carries a social stigma, which is the extent to which the need is perceived to have negative attributes or consequences that are implicitly deviant from norms (Leventhal, 1976a; McLaughlin et al., 2004). For example, a need associated with drug addiction is associated with a stronger stigma than a need stemming from family obligations (Colella, 2001). A need may evoke stigmatized responses in multiple ways. The nature of the need itself may be stigmatizing, such as in the case of an employee with congenital physical abnormalities that require accommodation (Stone \& Colella, 1996). Additionally, factors surrounding the need may stigmatize an otherwise normative need. For example, a request for maternity leave may have differing levels of stigma based on whether the employee is in a heterosexual or a same-sex relationship. Stigma may even occur from less direct sources (i.e., stigma by association), for instance, when an employee requests medical leave to care for a relative who is HIV-positive (Neuberg, Smith, Hoffman, $\&$ Russell, 1994). Regardless of its form, stigma impacts the should counterfactual process because the need's stigma marks the recipient as an "other," and as a result, the recipient is seen as less valuable or as morally defective (Goffman, 1963; Major \& O'Brien, 2005). Instead of feeling socially responsible, the actor would seek to distance himself or herself from the stigmatized need (Rai \& Fiske, 2011). Consequently, stigma likely elicits lower levels of should counterfactual thinking.

On the basis of the preceding discussion, we make the following propositions:

Proposition 4a: A need's particularism will increase an actor's should counterfactual thinking.

Proposition 4b: A need's stigma will decrease an actor's should counterfactual thinking.

Benefit to the Organization

Pragmatic considerations pertaining to the appropriate use of resources are important in organizational justice decisions (Johnson, Lanaj, \& Barnes, 2014; Scott et al., 2009). Early work by Leventhal and colleagues (1980) proposed that an actor would be more inclined to use a need allocation norm when satisfying the need would 
further the goals of the organization (McLean Parks, Conlon, Ang, \& Bontempo, 1999). A more recent empirical study by Conlon and colleagues (2004) gives support to this proposition by showing that allocations based on business-related needs activate participants' use of a need norm more frequently than those based on personal needs (such as financial difficulty from a recently laid-off spouse; McLean Parks et al., 1999). Thus, the greater the organizational benefits of using a need norm allocation, compared to a standard equity norm, are, the more likely it is to elicit actor should counterfactual thinking. For example, in an office where employees are abruptly directed to work from home, some employees may find that their equipment is inadequate for their work activity. In these situations, the manager is likely to consider that new equipment or high-speed internet connections should be provided only to those employees who need them.

Conversely, an actor is less likely to consider a need norm allocation as appropriate when satisfying the need does not benefit the organization's bottom line. For instance, a very productive employee's request to change from full-time to part-time, in order to take care of a dependent parent, has the potential to affect the employee's productivity, and therefore satisfying this need will likely hinder organizationally relevant goals (Colella, 2001). A need that fails to advance, or that even hurts, the bottom line may be less likely to elicit an actor's should counterfactual thinking associated with his or her responsibility to advance the organization's goals, leading to the selection of a more common equity norm instead.

ACT draws from the three attribution factors identified in Kelley's (1967) covariation model of attribution to forward consistency, consensus, and distinctiveness as predictors of an actor's should counterfactual thinking. Essentially, Kelley (1973: 108) argues that "an effect is attributed to the one of its possible causes with which, over time, it covaries." Traditionally, this has meant that an individual performs causal analysis based on the consistency, consensus, and distinctiveness of observed behaviors (Harvey, Madison, Martinko, Crook, \& Crook, 2014). Although attribution theory does acknowledge that individuals are inherently interested in understanding the causes of a status, attributions also serve to shape individuals' expectancies in terms of potential consequences (Martinko, Harvey, \& Dasborough, 2011); that is, individuals care about attributions not only because they want to understand why something occurred but also because attributions provide information on likely future impacts. Representing a shift from the traditional behavioralcausal focus of Kelley's three attribution dimensions (Harvey et al., 2014), ACT positions these constructs as need characteristics that predict an actor's attributions of a need's impact to the organization's bottom line. In doing so, ACT contributes to attribution theory by shifting Kelley's (1967) covariation between behavior and causes to a focus on covariation between need characteristics and impacts. This exemplifies the versatility of Kelley's three attributional dimensions while integrating these constructs with related attributional theory focused on principled decisionmaking (Brickman et al., 1982).

First, consistency captures the extent to which a need extends itself over time (Kelley, 1967). In addition to looking retrospectively at the characteristics of a need that have already arisen, actors are likely to evaluate a need in a prospective fashion 
(Weiner, 2012). Thus a need high in consistency creates a long-term burden on the organization that limits the amount and flexibility of resources that can be utilized toward future organizational opportunities. In light of an actor's responsibility to advance the organization's interests, this might cause an actor to view an allocation to a highly consistent need as less ethical, even when the actor's personal preference may have been to act in ways that would advance the recipient's well-being. Indeed, given the connection between justice and uncertainty (Lind \& Van den Bos, 2002), committing to a more consistent need may be considered an inappropriate use of an organization's resources given uncertain future conditions. In addition to consistency's impact on the organization's functioning, consistent needs potentially lead to compassion fatigue (Kinnick, Krugman, \& Cameron, 1996) and a greater view that allocations to such needs create an unsustainable dependence on behalf of the recipient, which ultimately may cause more harm when such resources are taken away (Perloff, 1987). The view that addressing individual needs can encourage recipients' dependency on such allocations and have a negative impact on organizational functioning is shared by Leventhal and colleagues (1980).

Consensus refers to the degree to which a need is similarly shared by others (Kelley, 1967). This can be thought of as the prevalence of a given need in the organization (Rothman, 2012). Needs with greater consensus are more disruptive to organizational functioning, and therefore it becomes incumbent on the actor (as an agent of the organization) to address them so that operations can continue uninterrupted. In this way, the attribution of responsibility to address needs high in consensus shifts from the recipient (who in cases of low consensus may be terminated or ignored) to the actor and organization, who now have the economic incentive to marshal resources to address the need (Brickman et al., 1982). In fact, owing to economies of scale, high-consensus needs (e.g., stress) may be more efficiently addressed by the organization (e.g., employee assistance programs), allowing recipients to be more productive employees, which ultimately benefits the organization (Joseph, Walker, \& Fuller-Tyszkiewicz, 2018). This logic may explain why certain high-consensus needs are addressed through organization-wide employee benefits and codified into policies. Because satisfying the need for recipients can mitigate negative impacts on the organization's bottom line, a need's consensus is likely to trigger increased should counterfactual thinking.

Finally, concerns about the impact of a need on the bottom line of an organization are also activated by the need's distinctiveness. Drawing from the attribution literature, distinctiveness refers to the extent to which a need is inconsistent with other characteristics of the recipient (Kelley \& Michela, 1980), such as his or her expressed values and beliefs, prior statuses, social networks, or personality. For example, a supervisor is likely to view a subordinate's need for an assistant to manage the subordinate's workload as a more distinctive need if this subordinate prides himself or herself on being independent and prefers working alone than if this subordinate has many friends and is extraverted. A distinctive need is more likely to be perceived as an exception and thus have less of an impact on the organization. Additionally, individuals generally desire consistency in their decisions (Festinger, 1957), so a distinctive need can be addressed without risking additional requests for 
need-based allocations in other areas. This prevents further obligating the actor to deviate from equity while allowing him or her to maintain consistency in treatment of the recipient. Finally, a distinctive need is less likely to evoke perceptions of unfairness from others in the organization and is thus less threatening to the functioning and harmony of an organization (Rahim, Magner, \& Shapiro, 2000). This is consistent with the notion that actors are typically hesitant to deviate from the default equity allocation norm because equity is generally perceived as most appropriate (Colquitt, 2001). We argue in ACT that a need's distinctiveness will increase benefit to the organization, thereby increasing an actor's should counterfactual thinking:

Proposition 5a: A need's consistency will decrease an actor's should counterfactual thinking.

Proposition 5b: A need's consensus will increase an actor's should counterfactual thinking.

Proposition 5c: A need's distinctiveness will increase an actor's should counterfactual thinking.

\section{Temporal Sequence of Would and Could Counterfactuals}

The question of the temporal ordering of counterfactuals was posed in Folger and Cropanzano's (2001) seminal theorizing. Specifically, Folger and Cropanzano note that "the Would judgment ... often brings about Could thinking . . . however, some Could judgments might actually precede Would judgments as foregone conclusions" (19). While subsequent research has left the temporal ordering of the counterfactuals arbitrary (Folger \& Cropanzano, 1998), Weiner's (1985a) attribution theory provides a more unqualified view on this dynamic. It outlines a temporal sequence that begins with an event observed by an individual. The event triggers a subsequent causal search in the observer to understand the reasons why this event occurred, and this causal search culminates in a behavioral reaction. Applied to ACT, the motivational sequence is initiated by an actor's perception that a need exists and an evaluation of its characteristics as the actor explores why and how the need came about (Weiner, 1985a, 1985b) to determine whether to use a need norm.

ACT integrates the attribution sequence from attribution theory with fairness theory by linking the use of would and could counterfactuals. As posited earlier, need characteristics that address the negativity of the need and the actor's awareness of the need will trigger an actor's would counterfactuals ("would the recipient have been better off had the need not presented itself?"). Based on attribution theory, we argue that it is this recognition of the existence and negativity of a need through would counterfactuals that activates the subsequent use of could counterfactuals ("could the recipient have behaved differently and in such a way that would have prevented, mitigated, or otherwise improved his or her unfavorable state of wellbeing?"). Here Weiner's (1985a) causal search is motivated by the unfavorable state of well-being. We previously made the case that causal search could be conceptualized as a form of could counterfactual thinking, hence we argue that increasing 
would counterfactual thinking is another path that motivates could counterfactual thinking. Although this sequence may be moderated by the flow of information as it becomes available to the actor (Folger \& Cropanzano, 1998), based on attribution theory (Weiner, 1985a), an actor's would counterfactual thinking, if and when it occurs, is likely to prompt an increase in could counterfactual thinking:

Proposition 6: An actor's would counterfactual thinking will increase his or her
could counterfactual thinking. Affective Consequences of Counterfactual Thinking

In addition to eliciting could counterfactual thinking, attribution theory proposes that the would counterfactual appraisal of a recipient's negative state of well-being activates an immediate affective response (Weiner, 1985a). In the context of need, a primary "moral emotion" is sympathy, the feeling of sorrow or concern for others triggered by their condition (Gerdes, 2011; Weiner, 2006). In ACT, we propose that sympathy is an automatic affective reaction to the recognition of an individual in need (i.e., greater would counterfactual thinking). On the basis of Weiner's (2006) logic, this automatic and implicit reaction means that would counterfactuals likely directly result in higher levels of sympathy from the actor toward the recipient.

In addition to this automatic process, ACT recognizes a more complex mediated process grounded in individuals' inherent tendency to judge others' deservingness of resources based on their conduct (Feather, 1999). According to the cognitionemotion sequence of attribution theory, causal search results in differing levels of sympathy because a recipient is seen as varying in his or her responsibility for the recipient's current predicament if he or she could have, but did not, behave in a different way that could have prevented, mitigated, or otherwise improved his or her unfavorable state of well-being (Weiner, 2006). As a result, an actor is also likely to consider a recipient's conduct in determining the recipient's deservingness of sympathy (Skitka \& Tetlock, 1992). After being triggered by would counterfactual thinking, could counterfactuals are an actor's attempt to judge a needy recipient's responsibility for his or her predicament. Those judged as more responsible naturally elicit less sympathy from an actor. Construed within the present framework, this mediation chain starts with 1) would counterfactual thinking, which then causes 2) varying levels of could counterfactual thinking, which ultimately determines 3) an actor's level of sympathy for a recipient. Compared to an automatic reaction, this process represents an alternative, more nuanced cognitive pathway to actor sympathy.

Should counterfactual thinking is also likely to increase an actor's sympathy toward the recipient because sympathy is a moral emotion (Weiner, 2006), and should counterfactuals address issues of morality and principles associated with a need. In particular, should counterfactuals align closely with the notion of moral imagination, which involves imagining the moral consequences of decisions. Moral imagination has been thought to predict sympathy because it allows one to better understand what another is feeling (Werhane, 1998). Altogether, this should cause the actor to feel more sympathy toward the recipient given that the recipient is likely 
now viewed as an individual who ought to be helped through an appropriate needbased allocation (Gray \& Wegner, 2011):

Proposition 7a: Would counterfactual thinking will increase an actor's sympathy toward the recipient.

Proposition 7b: Could counterfactual thinking will decrease an actor's sympathy toward the recipient.

Proposition 7c: Should counterfactual thinking will increase an actor's sympathy toward the recipient.

Proposition 7d: Could counterfactual thinking partially mediates the indirect relationship between would counterfactual thinking and an actor's sympathy toward the recipient.

\section{Behavioral Consequences of Counterfactual Thinking}

Emotions, including sympathy, can trigger a decision or action (Weiner, 2006). Past research in attribution theory has identified various forms of altruism as one such outcome of the attribution process (e.g., Betancourt, 1990; Reisenzein, 1986; Schmidt \& Weiner, 1988; Weiner, 1980). On the basis of these findings, we argue that an actor's sympathy toward the recipient likely predicts the actor's use of a need norm to allocate resources. This prediction dovetails with prior work in the disability literature that emphasizes the importance of sympathy in driving coworkers to use a need norm to judge the fairness of a colleague's disability accommodation (Colella, 2001; Stone \& Colella, 1996):

Proposition 8: An actor's sympathy toward the recipient will increase his or her use of a need norm to allocate resources to the recipient.

However, an actor's sympathy may not always result in the use of a need norm. After all, actors can leave sympathy unexpressed or unacted on (Leung, Chiu, \& Au, 1993). To further understand actors' need norm use, it is necessary to consider moderating factors, which scholars argue must be explored in organizational research (e.g., Johns, 2001, 2006; Rousseau \& Fried, 2001). Whereas Weiner's (2006) attribution theory is fundamentally mediational and focuses on general laws that transcend contexts, the ACT model explores moderating factors that may affect the impact of sympathy on need norm use in the context of organizational resource allocation decisions.

As established throughout this article, equity is the predominant allocation norm in organizations (Colquitt et al., 2001). In such a context where a need norm is rarely used (Törnblom \& Kazemi, 2015), an actor may struggle to balance the urge to apply a need norm (perhaps out of sympathy) with the normative pressure to employ equity as a basis for allocation decisions. The actor may even be surprised to find himself or herself desiring to make a need-based resource allocation due to an automatic affective motivation even though he or she typically makes decisions based on equity and rationality. This tension reflects the interplay between emotion and cognition in regulating motivation and behavior (Weiner, 2006). The 
dual-process nature of attribution theory (Barrett et al., 2004) suggests that automatic processes may be superseded (i.e., moderated) by controlled processes. That is, behavior results from the interaction between affective automatic processes and rational, controlled processes (Barrett et al., 2004). In the present model, sympathy is the primary affective driver of actors' need norm use, while should counterfactual thinking is a rational, controlled process that reflects both personal moral obligations and obligations to the organization within an organizational resource allocation context.

Therefore, should counterfactuals, as a form of controlled processing, are likely to moderate the influence of sympathy on an actor's need norm use by serving a regulatory role in selectively controlling the extent to which sympathy determines an actor's decision-making. The effect of sympathy on an actor's need norm use may be stronger when should counterfactuals suggest that it is consistent with principles, both those stemming from the organizational context and other moral obligations relevant to one in a position of power within the organization (Rai \& Fiske, 2011). That is, the larger the ethical gap in favor of a need-based allocation over an equity allocation is (i.e., greater should counterfactual thinking), the greater is the positive impact sympathy will have on an actor's need norm use. However, when should counterfactual thinking suggests otherwise, the effect of sympathy on an actor's need norm use may be attenuated. This expectation in ACT is consistent with justice research (e.g., Leventhal, 1980; Törnblom \& Kazemi, 2015), which proposes that an actor's ultimate allocation decision is the result of two competing forces: any potential alternatives to equity (e.g., need norm use driven by sympathy) versus equity considerations:

Proposition 9: An actor's should counterfactual thinking will moderate the relationship between his or her sympathy toward the recipient and the actor's use of a need norm to allocate resources to the recipient, such that greater should counterfactual thinking strengthens the relationship.

\section{DISCUSSION}

ACT outlines theoretically driven need characteristics that might meaningfully elicit the use of need-based resource allocation norms by actors. Integrating and drawing from fairness theory (Folger \& Cropanzano, 2001) and attribution theory (Weiner, 1985a), we propose that these factors impact would, could, and should counterfactuals, which are mental simulations of possible alternatives (Nicklin, 2013) and focus respectively on a recipient's state of well-being, the recipient's conduct, and the ethical principles surrounding the need-based allocation. This model follows Weiner's (2006) attributional model of motivation and emotion to explain the process that motivates actors to select a need norm as a basis for resource allocation. Finally, an organizationally relevant interaction is identified using tenets from justice research and fairness theory (Folger \& Cropanzano, 2001). In the following section, theoretical contributions and potential future research directions are discussed. 


\section{Theoretical Implications}

This theory takes several unique perspectives and has numerous implications for distributive justice research in particular and the justice literature more broadly. To begin with, the present article is the first attempt at an integrative theory addressing need-based resource allocation within the distributive justice paradigm. This focus represents a shift from equating equity with distributive justice to an exploration of the antecedents, processes, and moderators associated with distributive justice based on need. This framework provides a unique perspective by focusing on the need itself rather than actor attributes (Blader \& Rothman, 2014). The framework also embodies a change in focus from exogenous factors (i.e., external factors that cause actors to use a need-based resource allocation norm) to a precipitative view that emphasizes endogenous factors (i.e., factors associated with a need itself that might induce an actor's need norm use; Tepper, Duffy, Henle, \& Lambert, 2006).

Second, the need framework opens a new avenue of inquiry for researchers to examine whether certain needs have a higher risk of being denied resources than others. Our development of a theoretically driven typology of need characteristics is the initial foray into this research stream. Specifically, ACT outlines the multiple characteristics of a need that might impact individuals' use of a need-based resource allocation norm. In doing so, we acknowledge that needs are not all equal, and we expand the seemingly unidimensional black box of need into a multidimensional conceptualization. Furthermore, this need typology could provide a theoretical foundation for other research areas related to distributive justice that necessitate a framework to classify needs (e.g., altruism, prosocial, and disability literatures).

Third, ACT makes significant contributions to fairness theory and attribution theory by integrating these two well-established theories such that each bolsters the other. Attribution theory provides theoretical grounding for the specific need characteristics that elicit fairness theory's would, could, and should counterfactuals (Folger \& Cropanzano, 2001). In addition, attribution theory supplements the content perspective of fairness theory with a process perspective and builds on fairness theory's initial theorizing on the temporal ordering of the three counterfactuals (Folger \& Cropanzano, 2001). Together, they contribute to building a more robust theory that can simultaneously address both content and process questions in the justice literature (Greenberg, 1987). Additionally, taking an attributional process perspective results in the identification of sympathy as an affective mediator that drives actors' use of the need norm. This ultimately contributes to fairness theory by more fully realizing its original intention as a bridge between the justice and emotion literatures, rather than solely as a cognitive process used to form fairness judgments (Cropanzano et al., 2000).

The integration of fairness theory with attribution theory in ACT also brings significant contributions to attribution theory. For one, fairness theory details the cognitive dynamics implied in attribution theory, namely, the elucidation that causal search might be conceptualized as a form of counterfactual thinking. This has implications for examining causal search as a form of imagined thinking, opening avenues for integration with findings from the creativity literature (e.g., Markman, 
Lindberg, Kray, \& Galinsky, 2007). For example, models from the creativity literature (e.g., Amabile, 1983) might be applied to reveal meaningful antecedents to counterfactual thinking. Additionally, fairness theory provides the broad content domains of individual concern (i.e., state of well-being, conduct, and principles) that serve as the theoretical foundation and organizing framework for various need characteristics derived from attribution theory. Moreover, fairness theory allows for the mediational focus of attribution theory to be supplemented with a moderation perspective. With its emphasis on organizational issues, fairness theory was utilized to derive both the broad content domain (i.e., organizational principles) and cognitive dynamics (i.e., should counterfactuals) that might act as moderators to the affective mechanisms outlined in attribution theory. In doing so, ACT advances attribution theory by increasing its precision and richness within the context of organizations.

Finally, this article contributes to the broader justice literature in multiple ways. The most intuitive contribution is the application of counterfactuals to issues of need in organizations. These are two areas that have not been integrated; their integration highlights the central role that fairness theory plays in the justice literature (Colquitt \& Zipay, 2015). Also, fairness theory has primarily been applied to a rather narrow subset of distributive justice phenomena, namely, how recipients judge and react to an actor's adherence to equity in resource allocation decisions (Colquitt \& Zipay, 2015). This stems from the justice literature's emphasis on equity (Colquitt, 2001) and subordinate reactions (Scott et al., 2009). The current article extends the underlying theoretical mechanisms of fairness theory (i.e., counterfactuals) to 1) a distributive justice allocation other than equity, 2) recipients, and 3) actors' decisionmaking processes, as opposed to judgments of an actor's decisions. On one hand, this article applies counterfactuals to the use of need-based allocation norms and shifts the target of the counterfactual-based accountability process from the actor's actions to the recipient's needs. Though their form and context might differ (Nicklin et al., 2011), the present endeavor illustrates that counterfactuals can be not only utilized to examine the actions of actors but also meaningfully expanded to account for the actions, situations, and circumstances of other parties. On the other hand, fairness theory has chiefly been utilized to explain how individuals judge and react to an actor's decision. Yet, the present theory establishes that counterfactuals can also be elaborated upon to explain which factors cause actors to behave in certain ways in the first place (i.e., the actor's decision-making process). This represents further incorporation of the underresearched actor perspective into justice research (Scott et al., 2009).

\section{Future Research Directions}

The ACT model needs to be tested and can also be developed further in multiple ways.

Consistent with the body of research on affect's role in the formation of organizational justice perceptions (Barsky \& Kaplan, 2007), ACT might be advanced by examining the possibility of reciprocal relationships between sympathy and should 
counterfactuals, in which sympathy informs judgments of morality. Indeed, recent research suggests that even incidental emotions can influence moral judgments (Gawronski, Conway, Armstrong, Friesdorf, \& Hütter, 2018). In this way, it is possible that actors may experience spontaneous emotional reactions to a need (Weiner, 1985b), which then informs their moral cognitions in the form of should counterfactuals. For example, these spontaneous emotions may stem from moral dilemmas when the principles relevant to should counterfactuals conflict with each other (e.g., a moral obligation conflicting with a principle dictating organizational benefit). This internal emotional conflict could then inform an actor's moral judgments in the form of should counterfactual thinking. Although ACT does acknowledge the existence of immediate affective responses, as in the case of would counterfactuals directly eliciting sympathy (Weiner, 1985a), future research may examine the scope and nature of these fast affective reactions in terms of their impact on counterfactual cognitions, perhaps in a feedback loop over time.

Also, future research may examine other affective reactions/mediators in addition to sympathy. As mentioned, fairness theory (Folger \& Cropanzano, 2001) is fairly broad when noting that moral emotions may result from counterfactuals. Though this article drew on attribution theory (Weiner, 2006) to identify sympathy as the most crucial affective mediator, it is likely that other affective mediators may be operating in ACT as well. Of particular interest is empathy, which involves feeling what another is feeling (Gerdes, 2011), rather than the awareness of another's suffering that is characteristic of sympathy (Wispé, 1986). Given that empathy likely involves an actor's own experiences (Werhane, 1998; Wispé, 1986), a future expansion of ACT might involve characteristics of an actor that predict his or her cognitions and emotions elicited by need characteristics. Past research in the justice literature has identified the role of a manager's empathic concern in predicting interpersonal and informational justice (Patient \& Skarlicki, 2010). Perhaps empathy may be a more relevant affective mediator in predicting the effect of actor characteristics on need norm use, whereas sympathy may be more apt to transmit the effect of need characteristics. Future research should examine these possibilities.

Additionally, there is potential for examining meaningful interactions between the counterfactuals outlined in this theory. For example, Brickman and colleagues (1982) distinguish between attributions of responsibility for problems and attributions of responsibility for solutions. This parallels ACT's examination of 1) recipient conduct through could counterfactuals and 2) moral responsibility to address a need, a form of helping/solution, through should counterfactuals. In Brickman et al.'s model, attributions of a recipient's responsibility for problems and for solutions interact in a $2 \times 2$ matrix to form four distinct models of helping (recipient responsible or not responsible for causing the problem crossed with recipient responsible or not responsible for solutions). These four models of helping are then thought to predict differential actor and recipient behaviors. In a similar way, future research may expand on ACT and investigate interactions between could and should counterfactuals, as they relate to predicting recipient and actor attitudes and behaviors regarding need norm use. 
Future research might further examine the recipient-actor relationship by considering Rai and Fiske's (2011) relationship regulation theory. In this theory, need norm allocations are thought to spring from relationships where group members focus on commonalities and disregard individual identities (Giessner \& Van Quaquebeke, 2010). These relationships are guided by the moral motive of unity, which "is directed toward caring for and supporting the integrity of in-groups through a sense of collective responsibility and common fate" (Rai \& Fiske, 2011: 61). "In the context of fairness, people motivated by unity believe that goods should be shared freely without tracking and distributed based on need" (Rai, 2018: 233). Thus need norm use may vary based on the extent to which the unity motive is present in an actor-recipient relationship. In other relationships, individuals compare themselves with others based on input-outcome ratio values (Fiske, 1992). According to relationship regulation theory, the moral motive operating in such relationships is proportionality. "In the context of fairness, people motivated by proportionality believe that goods should be distributed based on merit" (Rai, 2018: 232). This is akin to the equity norm. Thus, from the perspective of this body of theory, need norm use is likely influenced by the nature of the relationship between an actor and a recipient, and ACT might be expanded to include these considerations. Indeed, this may only begin to scratch the surface of a complex subject, given that an actor and recipient may disagree on the nature of their relationship (i.e., they hold discrepant social-relational models). This may result in conflicting moral motives, should counterfactuals, and ultimately judgments (e.g., a recipient believes that a need norm is moral, while an actor believes an equity norm is moral; Brickman et al., 1982; Leventhal, 1976a). Adding another layer of complexity, relationship regulation theory acknowledges the potential simultaneous existence of multiple moral motives in any given actor-recipient relationship (Rai \& Fiske, 2011). This coincides with ACT's acknowledgement of multiple principles potentially impacting should counterfactuals. Thus, rather than focusing on need norm use as an actor's unilateral decision, inclusion of the relationship dynamics between the actor and the recipient (based on relationship regulation theory) brings the social-relational context to bear on ACT and represents a fruitful next step.

\section{Acknowledgements}

We thank the management faculties at Florida Gulf Coast University; California State University, Chico; and Portland State University for their insights and support. We also acknowledge the helpful feedback from two anonymous referees and associate editor Gary Weaver.

\section{REFERENCES}

Adams, J. S. 1965. Inequity in social exchange. In L. Berkowitz (Ed.), Advances in experimental social psychology, vol. 2: 267-300. New York: Academic Press.

Amabile, T. M. 1983. The social psychology of creativity: A componential conceptualization. Journal of Personality and Social Psychology, 45(2): 357-76. 
Amabile, T. M. 1985. Motivation and creativity: Effects of motivational orientation on creative writers. Journal of Personality and Social Psychology, 48(2): 393-99.

Baer, M., Frank, E. L., Matta, F. K., Luciano, M. M., \& Wellman, N. 2020. Under trusted, over trusted, or just right? The fairness of (in)congruence between trust wanted and trust received. Academy of Management Journal. DOI: 10.5465/amj.2018.0334.

Barrett, L. F., Tugade, M. M., \& Engle, R. W. 2004. Individual differences in working memory capacity and dual-process theories of the mind. Psychological Bulletin, 130 (4): 553-73.

Barsky, A., \& Kaplan, S. A. 2007. If you feel bad, it's unfair: A quantitative synthesis of affect and organizational justice perceptions. Journal of Applied Psychology, 92(1): 286-95.

Berkowitz, L. 1972. Social norms, feelings, and other factors affecting helping behavior. In L. Berkowitz (Ed.), Advances in experimental social psychology, vol. 6: 63-108. New York: Academic Press.

Berkowitz, L., \& Connor, W. H. 1966. Success, failure, and social responsibility. Journal of Personality and Social Psychology, 4(6): 664-69.

Berkowitz, L., \& Daniels, L. R. 1963. Responsibility and dependency. Journal of Abnormal and Social Psychology, 66(5): 429-36.

Berkowitz, L., \& Daniels, L. R. 1964. Affecting the salience of the social responsibility norm: Effects of past help on the response to dependency relationships. Journal of Abnormal and Social Psychology, 68(3): 275-81.

Berscheid, E., Graziano, W., Monson, T., \& Dermer, M. 1976. Outcome dependency: Attention, attribution, and attraction. Journal of Personality and Social Psychology, 34(5): 978-89.

Betancourt, H. 1990. An attribution-empathy model of helping behavior: Behavioral intentions and judgments of help-giving. Personality and Social Psychology Bulletin, 16 (3): 573-91.

Blader, S. L., \& Rothman, N. B. 2014. Paving the road to preferential treatment with good intentions: Empathy, accountability and fairness. Journal of Experimental Social Psychology, 50: 65-81.

Brickman, P., Rabinowitz, V. C., Karuza, J., Coates, D., Cohn, E., \& Kidder, L. 1982. Models of helping and coping. American Psychologist, 37(4): 368-84.

Carretié, L. 2014. Exogenous (automatic) attention to emotional stimuli: A review. Cognitive, Affective, and Behavioral Neuroscience, 14(4): 1228-58.

Colella, A. 2001. Coworker distributive fairness judgments of the workplace accommodation of employees with disabilities. Academy of Management Review, 26(1): $100-116$.

Colquitt, J. A. 2001. On the dimensionality of organizational justice: A construct validation of a measure. Journal of Applied Psychology, 86(3): 386-400.

Colquitt, J. A., Conlon, D. E., Wesson, M. J., Porter, C. O., \& Ng, K. Y. 2001. Justice at the millennium: A meta-analytic review of 25 years of organizational justice research. Journal of Applied Psychology, 86(3): 425-45.

Colquitt, J. A., Greenberg, J., \& Zapata-Phelan, C. P. 2005. What is organizational justice? A historical overview. In J. Greenberg \& J. A. Colquitt (Eds.), Handbook of organizational justice: 1-56. Mahwah, NJ: Lawrence Erlbaum.

Colquitt, J. A., \& Rodell, J. B. 2015. Measuring justice and fairness. In R. Cropanzano \& M. L. Ambrose (Eds.), The Oxford handbook of justice in the workplace, vol. 1: 187-202. New York: Oxford University Press. 
Colquitt, J. A., Scott, B. A., Rodell, J. B., Long, D. M., Zapata, C. P., Conlon, D. E., \& Wesson, M. J. 2013. Justice at the millennium, a decade later: A meta-analytic test of social exchange and affect-based perspectives. Journal of Applied Psychology, 98 (2): 199-236.

Colquitt, J. A., \& Zipay, K. P. 2015. Justice, fairness, and employee reactions. Annual Review of Organizational Psychology and Organizational Behavior, 2: 75-99.

Conlon, D. E., Porter, C. O., \& Parks, J. M. 2004. The fairness of decision rules. Journal of Management, 30(3): 329-49.

Cropanzano, R., Fortin, M., \& Kirk, J. F. 2015. How do we know when we are treated fairly? Justice rules and fairness judgments. In M. R. Buckley, J. R. B. Halbesleben, \& A. R. Wheeler (Eds.), Research in personnel and human resources management, vol. 33: 279-350. Bingley, UK: Emerald Group.

Cropanzano, R., Massaro, S., \& Becker, W. J. 2017. Deontic justice and organizational neuroscience. Journal of Business Ethics, 144(4): 733-54.

Cropanzano, R., Weiss, H. M., Suckow, K. J., \& Grandey, A. A. 2000. Doing justice to workplace emotion. In N. M. Ashkanasy, C. E. Härtel, \& W. J. Zerbe (Eds.), Emotions in the workplace: Research, theory, and practice: 49-62. Westport, CT: Quorum Books/Greenwood.

Deutsch, M. 1975. Equity, equality, and need: What determines which value will be used as the basis of distributive justice? Journal of Social Issues, 31(3): 137-49.

Ebneter, D. S., Latner, J. D., \& O’Brien, K. S. 2011. Just world beliefs, causal beliefs, and acquaintance: Associations with stigma toward eating disorders and obesity. Personality and Individual Differences, 51(5): 618-22.

Feather, N. T. 1999. Judgments of deservingness: Studies in the psychology of justice and achievement. Personality and Social Psychology Review, 3(2): 86-107.

Feldman, R. E. 1968. Response to compatriot and foreigner who seek assistance. Journal of Personality and Social Psychology, 10(3): 202-14.

Festinger, L. 1957. A theory of cognitive dissonance. Evanston, IL: Row-Peterson.

Fiske, A. P. 1992. The four elementary forms of sociality: Framework for a unified theory of social relations. Psychological Review, 99(4): 689-723.

Fiske, S. T., \& Taylor, S. E. 2013. Social cognition: From brains to culture. Thousand Oaks, CA: Sage.

Foa, E. B., \& Foa, U. G. 2012. Resource theory of social exchange. In K. Tornblom \& A. Kazemi (Eds.), Handbook of social resource theory: Theoretical extensions, empirical insights, and social applications: 15-32. New York: Springer.

Foa, U. G., \& Foa, E. B. 1980. Resource theory: Interpersonal behavior as exchange. In K. J. Gergen, M. S. Greenberg, \& R. H. Willis (Eds.), Social exchange: Advances in theory and research: 77-94. New York: Plenum.

Folger, R. 1994. Workplace justice and employee worth. Social Justice Research, 7(3): 225-40.

Folger, R. 1998. Fairness as a moral virtue. In M. Schminke (Ed.), Managerial ethics: Moral management of people and processes: 13-34. Mahwah, NJ: Lawrence Erlbaum.

Folger, R. G., \& Cropanzano, R. 1998. Organizational justice and human resource management. Thousand Oaks, CA: Sage.

Folger, R., \& Cropanzano, R. 2001. Fairness theory: Justice as accountability. In J. Greenberg (Ed.), Advances in organizational justice, vol. 1: 1-55. Stanford, CA: Stanford University Press.

Folger, R., Cropanzano, R., \& Goldman, B. 2005. What is the relationship between justice and morality? In J. Greenberg \& J. A. Colquitt (Eds.), Handbook of organizational justice: 215-45. Mahwah, NJ: Lawrence Erlbaum. 
Gawronski, B., Conway, P., Armstrong, J., Friesdorf, R., \& Hütter, M. 2018. Effects of incidental emotions on moral dilemma judgments: An analysis using the CNI model. Emotion, 18(7): 989-1008.

Gerdes, K. E. 2011. Empathy, sympathy, and pity: 21st-century definitions and implications for practice and research. Journal of Social Service Research, 37(3): 230-41.

Gersick, C. J. G. 1991. Revolutionary change theories: A multilevel exploration of the punctuated equilibrium paradigm. Academy of Management Review, 16(1): 10-36.

Giessner, S., \& Van Quaquebeke, N. 2010. Using a relational models perspective to understand normatively appropriate conduct in ethical leadership. Journal of Business Ethics, 95(1): 43-55.

Goffman, E. 1963. Stigma: Notes on the management of spoiled identity. New York: Prentice Hall.

Graen, G. B., \& Uhl-Bien, M. 1995. Relationship-based approach to leadership: Development of leader-member exchange (LMX) theory of leadership over 25 years: Applying a multi-level multi-domain perspective. Leadership Quarterly, 6(2): 219-47.

Gray, K., \& Wegner, D. M. 2011. Dimensions of moral emotions. Emotion Review, 3(3): 258-60.

Greenberg, J. 1987. A taxonomy of organizational justice theories. Academy of Management Review, 12(1): 9-22.

Harvey, P., Madison, K., Martinko, M., Crook, T. R., \& Crook, T. A. 2014. Attribution theory in the organizational sciences: The road traveled and the path ahead. Academy of Management Perspectives, 28(2): 128-46.

He, W., Chen, C. C., \& Zhang, L. 2004. Rewards-allocation preferences of Chinese employees in the new millennium: The effects of ownership reform, collectivism, and goal priority. Organization Science, 15(2): 221-31.

Johns, G. 2001. In praise of context. Journal of Organizational Behavior, 22(1): 31-42.

Johns, G. 2006. The essential impact of context on organizational behavior. Academy of Management Review, 31(2): 386-408.

Johnson, R. E., Lanaj, K., \& Barnes, C. M. 2014. The good and bad of being fair: Effects of procedural and interpersonal justice behaviors on regulatory resources. Journal of Applied Psychology, 99(4): 635-50.

Joseph, B., Walker, A., \& Fuller-Tyszkiewicz, M. 2018. Evaluating the effectiveness of employee assistance programmes: A systematic review. European Journal of Work and Organizational Psychology, 27(1): 1-15.

Kanfer, R., \& Ackerman, P. L. 1989. Motivation and cognitive abilities: An integrative/ aptitude-treatment interaction approach to skill acquisition. Journal of Applied Psychology, 74(4): 657-90.

Kelley, H. H. 1967. Attribution theory in social psychology. In D. Levine (Ed.), Nebraska Symposium on Motivation, 1967. Lincoln: University of Nebraska Press.

Kelley, H. H. 1973. The processes of causal attribution. American Psychologist, 28(2): 107-28.

Kelley, H. H., \& Michela, J. L. 1980. Attribution theory and research. Annual Review of Psychology, 31(1): 457-501.

Kim, K. I., Park, H. J., \& Suzuki, N. 1990. Reward allocations in the United States, Japan, and Korea: A comparison of individualistic and collectivistic cultures. Academy of Management Journal, 33(1): 188-98.

Kinnick, K. N., Krugman, D. M., \& Cameron, G. T. 1996. Compassion fatigue: Communication and burnout toward social problems. Journalism and Mass Communication Quarterly, 73: 687-707. 
Lamm, H., \& Schwinger, T. 1980. Norms concerning distributive justice: Are needs taken into consideration in allocation decisions? Social Psychology Quarterly, 43: 425-29.

Leung, K., Chiu, W.-H., \& Au, Y. 1993. Sympathy and support for industrial actions: A justice analysis. Journal of Applied Psychology, 78(5): 781-87.

Leventhal, G. S. 1976a. The distribution of rewards and resources in groups and organizations. In L. Berkowitz \& E. Walster (Eds.), Advances in experimental social psychology, vol. 9: 91-131. New York: Academic Press.

Leventhal, G. S. 1976b. Fairness in social relationships. In J. W. Thibaut, J. T. Spence, \& R. C. Carson (Eds.), Contemporary topics in social psychology: 211-40. Morristown, NJ: General Learning Press.

Leventhal, G. S. 1980. What should be done with equity theory? In K. J. Gergen, M. S. Greenberg, \& R. H. Willis (Eds.), Social exchange: Advances in theory and research: 27-55. New York: Plenum Press.

Leventhal, G. S., Karuza, J., \& Fry, W. R. 1980. Beyond fairness: A theory of allocation preferences. In G. Mikula (Ed.), Justice and social interaction, vol. 3: 167-218. New York: Springer.

Lind, E. A., \& Van den Bos, K. 2002. When fairness works: Toward a general theory of uncertainty management. In B. M. Staw \& R. M. Kramer (Eds.), Research in organizational behavior, vol. 24: 181-223. Greenwich, CT: JAI Press.

Major, B., \& O'Brien, L. T. 2005. The social psychology of stigma. Annual Review of Psychology, 56: 393-421.

Mannix, E. A., Neale, M. A., \& Northcraft, G. B. 1995. Equity, equality, or need? The effects of organizational culture on the allocation of benefits and burdens. Organizational Behavior and Human Decision Processes, 63(3): 276-86.

Mantler, J., Schellenberg, E. G., \& Page, J. S. 2003. Attributions for serious illness: Are controllability, responsibility and blame different constructs? Canadian Journal of Behavioural Science, 35(2): 142-52.

Markham, S. E., Scott, K., \& McKee, G. 2002. Recognizing good attendance: A longitudinal, quasi-experimental field study. Personnel Psychology, 55(3): 639-60.

Markman, K. D., Lindberg, M. J., Kray, L. J., \& Galinsky, A. D. 2007. Implications of counterfactual structure for creative generation and analytical problem solving. Personality and Social Psychology Bulletin, 33(3): 312-24.

Martin, J., \& Harder, J. W. 1994. Bread and roses: Justice and the distribution of financial and socioemotional rewards in organizations. Social Justice Research, 7(3): 241-64.

Martin, R., Guillaume, Y., Thomas, G., Lee, A., \& Epitropaki, O. 2016. Leader-member exchange (LMX) and performance: A meta-analytic review. Personnel Psychology, 69(1): 67-121.

Martinko, M. J., Harvey, P., \& Dasborough, M. T. 2011. Attribution theory in the organizational sciences: A case of unrealized potential. Journal of Organizational Behavior, 32(1): 144-49.

Martinko, M. J., \& Thomson, N. F. 1998. A synthesis and extension of the Weiner and Kelley attribution models. Basic and Applied Social Psychology, 20(4): 271-84.

McLaughlin, M. E., Bell, M. P., \& Stringer, D. Y. 2004. Stigma and acceptance of persons with disabilities: Understudied aspects of workforce diversity. Group and Organization Management, 29(3): 302-33.

McLean Parks, J., Conlon, D. E., Ang, S., \& Bontempo, R. 1999. The manager giveth, the manager taketh away: Variation in distribution/recovery rules due to resource type and cultural orientation. Journal of Management, 25(5): 723-57. 
Neuberg, S. L., Smith, D. M., Hoffman, J. C., \& Russell, F. J. 1994. When we observe stigmatized and "normal" individuals interacting: Stigma by association. Personality and Social Psychology Bulletin, 20(2): 196-209.

Nicklin, J. M. 2013. Expertise, counterfactual thinking, and fairness perceptions: A test of fairness theory. Social Justice Research, 26(1): 42-60.

Nicklin, J. M., Greenbaum, R., McNall, L. A., Folger, R., \& Williams, K. J. 2011. The importance of contextual variables when judging fairness: An examination of counterfactual thoughts and fairness theory. Organizational Behavior and Human Decision Processes, 114(2): 127-41.

Patient, D. L., \& Skarlicki, D. P. 2010. Increasing interpersonal and informational justice when communicating negative news: The role of the manager's empathic concern and moral development. Journal of Management, 36(2): 555-78.

Perloff, R. 1987. Self-interest and personal responsibility redux. American Psychologist, 42(1): 3-11.

Poepsel, D. L., \& Schroeder, D. A. 2013. Joining groups: How resources are to be divided matters. Group Dynamics: Theory, Research, and Practice, 17(3): 180-93.

Rahim, M. A., Magner, N. R., \& Shapiro, D. L. 2000. Do justice perceptions influence styles of handling conflict with supervisors? What justice perceptions, precisely? International Journal of Conflict Management, 11(1): 9-31.

Rai, T. S. 2018. Relationship regulation theory. In J. Graham \& K. Gray (Eds.), Atlas of moral psychology: 231-40. New York: Guilford Press.

Rai, T. S., \& Fiske, A. P. 2011. Moral psychology is relationship regulation: Moral motives for unity, hierarchy, equality, and proportionality. Psychological Review, 118(1): $57-75$.

Reisenzein, R. 1986. A structural equation analysis of Weiner's attribution-Affect model of helping behavior. Journal of Personality and Social Psychology, 50(6): 1123-33.

Rothman, K. J. 2012. Epidemiology: An introduction (2nd ed.). New York: Oxford University Press.

Rousseau, D. M., \& Fried, Y. 2001. Location, location, location: Contextualizing organizational research. Journal of Organizational Behavior, 22(1): 1-13.

Rupp, D. E., Shapiro, D. L., Folger, R., Skarlicki, D. P., \& Shao, R. 2017. A critical analysis of the conceptualization and measurement of organizational justice: Is it time for reassessment? Academy of Management Annals, 11(2): 919-59.

Sabat, I. E., Lindsey, A. P., Membere, A., Anderson, A., Ahmad, A., King, E., \& Bolunmez, B. 2014. Invisible disabilities: Unique strategies for workplace allies. Industrial and Organizational Psychology, 7(2): 259-65.

Santuzzi, A. M., Waltz, P. R., Finkelstein, L. M., \& Rupp, D. E. 2014. Invisible disabilities: Unique challenges for employees and organizations. Industrial and Organizational Psychology, 7(2): 204-19.

Schmidt, G., \& Weiner, B. 1988. An attribution-affect-action theory of behavior: Replications of judgments of help-giving. Personality and Social Psychology Bulletin, 14 (3): $610-21$.

Schwartz, S. 1975. The justice of need and the activation of humanitarian norms. Journal of Social Issues, 31(3): 111-36.

Scott, B. A., Colquitt, J. A., \& Paddock, E. L. 2009. An actor-focused model of justice rule adherence and violation: The role of managerial motives and discretion. Journal of Applied Psychology, 94(3): 756-69. 
Scott, B. A., Garza, A. S., Conlon, D. E., \& Kim, Y. J. 2014. Why do managers act fairly in the first place? A daily investigation of "hot" and "cold" motives and discretion. Academy of Management Journal, 57(6): 1571-91.

Serences, J. T., \& Yantis, S. 2007. Spatially selective representations of voluntary and stimulus-driven attentional priority in human occipital, parietal, and frontal cortex. Cerebral Cortex, 17(2): 284-93.

Skarlicki, D. P., \& Kulik, C. T. 2004. Third-party reactions to employee (mis) treatment: A justice perspective. Research in Organizational Behavior, 26: 183-229.

Skitka, L. J., \& Tetlock, P. E. 1992. Allocating scarce resources: A contingency model of distributive justice. Journal of Experimental Social Psychology, 28(6): 491-522.

Slaughter, J. E., Cable, D. M., \& Turban, D. B. 2014. Changing job seekers' image perceptions during recruitment visits: The moderating role of belief confidence. Journal of Applied Psychology, 99(6): 1146-58.

Son Hing, L. S., Bobocel, D. R., \& Zanna, M. P. 2002. Meritocracy and opposition to affirmative action: Making concessions in the face of discrimination. Journal of Personality and Social Psychology, 83(3): 493-509.

Stone, D. L., \& Colella, A. 1996. A model of factors affecting the treatment of disabled individuals in organizations. Academy of Management Review, 21(2): 352-401.

Sutton, R. I., \& Staw, B. M. 1995. What theory is not. Administrative Science Quarterly, 40 (3): 371-84.

Sweeny, K. 2008. Crisis decision theory: Decisions in the face of negative events. Psychological Bulletin, 134(1): 61-76.

Swider, B. W., Liu, J. T., Harris, T. B., \& Gardner, R. G. 2017. Employees on the rebound: Extending the careers literature to include boomerang employment. Journal of Applied Psychology, 102(6): 890-909.

Tepper, B. J., Duffy, M. K., Henle, C. A., \& Lambert, L. S. 2006. Procedural injustice, victim precipitation, and abusive supervision. Personnel Psychology, 59(1): 101-23.

Törnblom, K., \& Kazemi, A. 2015. Distributive justice: Revisiting past statements and reflecting on future prospects. In R. Cropanzano \& M. L. Ambrose (Eds.), The Oxford handbook of justice in the workplace: 15-50. New York: Oxford University Press.

Webb Day, J. W., Holladay, C. L., Johnson, S. K., \& Barron, L. G. 2014. Organizational rewards: Considering employee need in allocation. Personnel Review, 43(1): 74-95.

Weick, K. E. 1995. What theory is not, theorizing is. Administrative Science Quarterly, 40 (3): 385-90.

Weiner, B. 1979. A theory of motivation for some classroom experiences. Journal of Educational Psychology, 71(1): 3-25.

Weiner, B. 1980. A cognitive (attribution)-emotion-action model of motivated behavior: An analysis of judgments of help-giving. Journal of Personality and Social Psychology, 39(2): 186-200.

Weiner, B. 1985a. An attributional theory of achievement motivation and emotion. Psychological Review, 92(4): 548-73.

Weiner, B. 1985b. "Spontaneous" causal thinking. Psychological Bulletin, 97(1): 74-84.

Weiner, B. 2006. Social motivation, justice, and the moral emotions: An attributional approach. Mahwah, NJ: Lawrence Erlbaum.

Weiner, B. 2010. Attribution theory. In I. B. Weiner \& W. E. Craighead (Eds.), Corsini encyclopedia of psychology, vol. 4: 1-2. Hoboken, NJ: John Wiley. 
Weiner, B. 2012. An attribution theory of motivation. In P. A. M. Van Lange, A. W. Kruglanski, \& E. T. Higgins (Eds.), Handbook of theories of social psychology, vol. 1: 135-55. Thousand Oaks, CA: Sage.

Werhane, P. H. 1998. Moral imagination and the search for ethical decision-making in management. Business Ethics Quarterly, 8: 75-98.

Wispé, L. 1986. The distinction between sympathy and empathy: To call forth a concept, a word is needed. Journal of Personality and Social Psychology, 50(2): 314-21.

JosEPH T. LIU (jtliu@fgcu.edu, corresponding author) is an assistant professor of management in the Lutgert College of Business at Florida Gulf Coast University. He received his $\mathrm{PhD}$ from the Scheller College of Business at the Georgia Institute of Technology. His research interests include organizational justice, ethics, human resource management, and management education.

Maria J. Mendez is an assistant professor in the Department of Management of California State University, Chico. Mendez's research centers on shared leadership, although she has also published in the areas of followership, global leadership, and management education. She received a PhD in business administration from New Mexico State University.

This is an Open Access article, distributed under the terms of the Creative Commons Attribution licence (http://creativecommons.org/licenses/by/4.0/), which permits unrestricted re-use, distribution, and reproduction in any medium, provided the original work is properly cited. 